Research Paper

\title{
Saccharomyces cerevisiae and non-Saccharomyces yeasts in grape varieties of the São Francisco Valley
}

\author{
Camila M.P.B.S. de Ponzzes-Gomes ${ }^{1,2}$, Dângelly L.F.M. de Mélo ${ }^{1}$, \\ Caroline A. Santana ${ }^{1}$, Giuliano E. Pereira ${ }^{3}$, Michelle O.C. Mendonça ${ }^{4}$, \\ Fátima C.O. Gomes ${ }^{5}$, Evelyn S. Oliveira ${ }^{6}$, Antonio M. Barbosa $\mathrm{Jr}^{1}$, \\ Rita C. Trindade ${ }^{1}$, Carlos A. Rosa ${ }^{4}$ \\ ${ }^{1}$ Laboratório de Microbiologia Aplicada, Departamento de Morfologia, Universidade Federal de Sergipe, \\ São Cristóvão, SE, Brazil. \\ ${ }^{2}$ Programa de Pós-Graduação em Biotecnologia, Universidade Estadual de Feira de Santana, \\ Feira de Santana, BA, Brazil. \\ ${ }^{3}$ Embrapa Uva e Vinho/Semi-Árido, Petrolina, PE, Brazil. \\ ${ }^{4}$ Departamento de Microbiologia, Instituto de Ciências Biológicas, \\ Universidade Federal de Minas Gerais, Belo Horizonte, MG, Brazil. \\ ${ }^{5}$ Departamento de Química, Centro Federal de Ensino Tecnológico, Belo Horizonte, MG, Brazil. \\ ${ }^{6}$ Departamento de Alimentos, Faculdade de Farmácia, Universidade Federal de Minas Gerais, \\ Belo Horizonte, MG, Brazil.
}

Submitted: November 15, 2012; Approved: September 9, 2013.

\begin{abstract}
The aims of this work was to characterise indigenous Saccharomyces cerevisiae strains in the naturally fermented juice of grape varieties Cabernet Sauvignon, Grenache, Tempranillo, Sauvignon Blanc and Verdejo used in the São Francisco River Valley, northeastern Brazil. In this study, $155 S$. cerevisiae and 60 non-Saccharomyces yeasts were isolated and identified using physiological tests and sequencing of the D1/D2 domains of the large subunit of the rRNA gene. Among the non-Saccharomyces species, Rhodotorula mucilaginosa was the most common species, followed by Pichia kudriavzevii, Candida parapsilosis, Meyerozyma guilliermondii, Wickerhamomyces anomalus, Kloeckera apis, P. manshurica, C. orthopsilosis and C. zemplinina. The population counts of these yeasts ranged among 1.0 to $19 \times 10^{5} \mathrm{cfu} / \mathrm{mL}$. A total of 155 isolates of $S$. cerevisiae were compared by mitochondrial DNA restriction analysis, and five molecular mitochondrial DNA restriction profiles were detected. Indigenous strains of S. cerevisiae isolated from grapes of the São Francisco Valley can be further tested as potential starters for wine production.
\end{abstract}

Key words: Brazilian wines, Saccharomyces cerevisiae, indigenous strains, non-Saccharomyces, mitochondrial DNA restriction analysis.

\section{Introduction}

Winemaking in the semi-arid region of the São Francisco River Valley, northeastern Brazil has grown rapidly in recent years, leading to the production of approximately 7 million litres of wine per year. The ability to produce two to three crops of grapes (Vitis vinifera L.) per year due to favourable weather conditions distinguishes this region from traditional winemaking areas in Brazil and the world. This region has an annual average temperature of $26^{\circ} \mathrm{C}$ and water available for irrigation. These vineyards are cultivated on the banks of the São Francisco River between latitudes 8 and $9^{\circ}$ South and between the Brazilian states of Bahia and Pernambuco. The cultivars used in this region are Cabernet Sauvignon, Grenache, Tempranillo, Sauvignon Blanc, Syrah and Verdejo (Santos, 2008).

Send correspondence to C.A. Rosa. Departamento de Microbiologia, Instituto de Ciências Biológicas, Universidade Federal de Minas Gerais, Caixa Postal 486, 31270-901 Belo Horizonte, MG, Brazil. E-mail: carlrosa@icb.ufmg.br. 
Several authors have investigated the origin of Saccharomyces cerevisiae strains that are responsible for spontaneous grape must fermentation (Esteve-Zarzoso et al., 2000; Clemente-Jimenez et al., 2004; Schuller et al., 2005, Valero et al., 2007; Wang and Liu, 2013). Some authors contend that $S$. cerevisiae comes from the microbial community resident in wineries. In the vineyard, yeasts may be transported from the soil to the grapes by insects or by the wind (Valero et al., 2007). Autochthonous winery-resident strains of $S$. cerevisiae take over graperesident yeasts and predominate in natural fermentations (Ciani et al., 2004; Settanni et al., 2012; Lederer et al., 2013). Damaged grape berries are rich depositories of $S$. cerevisiae, demonstrating that the vineyard can be a natural reservoir of this yeast (Valero et al., 2007). Moreover, the diversity of $S$. cerevisiae strains differs according to each plant and grape cluster. For this reason, it is not always possible to obtain the beverage with the same sensorial quality from spontaneous wine fermentation (Clemente-Jimenez et al., 2004).

Indigenous strains of $S$. cerevisiae have been shown to be better adapted to their local environmental conditions and substrates than non-indigenous strains (Esteve-Zarzoso et al., 2000; Fleet, 2008; Urso et al., 2008; Capece et al., 2012). These indigenous strains may contribute to the overall sensorial quality of wine because they are more competitive in their local environmental conditions and they assure the maintenance of the typical sensorial properties of the wines produced in a particular region (Schuller et al., 2005; Valero et al., 2007; Settanni et al., 2012). During alcoholic fermentation, these $S$. cerevisiae strains can release various aroma compounds, which influence the organoleptic quality of wines (Capece et al., 2012). Thus, the aims of this study were as follows: (i) to isolate and identify the yeasts from fermented musts of five grape varieties used in the production of wine in the São Francisco Valley; and (ii) to characterise strains of $S$. cerevisiae by mitochondrial DNA restriction analysis (mtDNA-RFLP).

\section{Materials and Methods}

\section{Sampling and yeast isolation}

Samples were collected between July and September 2008 at Fazenda Ouro Verde / Miolo in the semi-arid Sao Francisco Valley region, municipality of Casa Nova, Bahia, Brazil. The grape varieties used in this work were the red grapes Tempranillo, Cabernet Sauvignon and Grenache and the white grapes Sauvignon Blanc and Verdejo. In each vineyard, six sampling points were defined, and the distance between the points varied between 80 and $100 \mathrm{~m}$.

Approximately $2 \mathrm{~kg}$ of grapes were collected aseptically in sterile plastic bags, transported to the laboratory in an ice bath and processed in no more than $48 \mathrm{~h}$. From each sampling point, grapes were crushed, and the grape juice was fermented at $20^{\circ} \mathrm{C}$ in small volumes $(500 \mathrm{~mL})$ (Schul- ler et al., 2005). Fermentation evolution was monitored daily until the sugar content was reduced to $70 \mathrm{~g} / \mathrm{L}$, corresponding to the consumption of approximately $2 / 3$ of the sugar content and/or before 15 days had passed.

Serial 10-fold dilutions of the samples were inoculated $(0.1 \mathrm{~mL})$ in triplicate on YM agar (yeast extract-malt extract agar, glucose $1 \%$, malt extract $0.3 \%$, yeast extract $0.3 \%$, peptone $0.5 \%$, agar $2 \%$ and chloramphenicol $0.01 \%$ ) for the isolation of $S$. cerevisiae strains and other yeasts and on lysine agar (yeast carbon base $1.17 \%$, lysine $0.056 \%$, agar $2 \%$ and $0.01 \%$ chloramphenicol) for isolation of only non-Saccharomyces yeasts. Plates containing between 30 and 300 yeast colonies were examined. From each grape fermentation, ten colonies of the most prevalent yeast morphotype on the YM plates were purified, and each different yeast morphotype was also counted and purified for later identification. From the lysine agar plates, each different yeast morphotype was counted and purified for later identification.

\section{Identification and molecular characterisation of yeasts isolated from fermented must}

The yeasts were identified by the standard methods of Kurtzman et al. (2011). Yeast identities were confirmed by sequencing the D1/D2 variable domains of the large subunit of the rRNA gene; the D1/D2 divergent domains were PCR-amplified as described by Lachance et al. (1999) using the primers NL-1 (5'-GCATATCAATAAGCG GAGGAAAAG-3') and NL-4 (5'-GGTCCGTGTTTCAA GACGG-3'). Identities of badisiomycetous species were also confirmed by sequencing the intergenic transcribed spacer (ITS) 1-5.8S-ITS2 region of the large-subunit rRNA gene (10). The amplified DNA was concentrated and purified with WizardSV columns (Promega, USA) and then sequenced in a MegaBACE 1000 automated sequencing system (Amersham Biosciences, USA). The sequences were edited with the program DNAMAN, version 4.1 (Lynnon Bio-Soft, Canada). Existing sequences for other yeasts were retrieved from GenBank.

All isolates previously identified as $S$ cerevisiae were compared using mitochondrial DNA (mtDNA) restriction analysis. To verify whether the strains found in this study were indigenous, comparisons were made with five commercial strains of $S$. cerevisiae and one commercial strain of $S$. bayanus used in the São Francisco Valley region. The names of the supplier companies have been substituted by capital letters from A to F. These strains were $S$. cerevisiae (A, B, C, D, E) and $S$. bayanus (F). The mtDNA of isolates was purified as described by Querol et al. (1992), and digested with Hinfl restriction endonuclease (Invitrogen, USA). The restriction fragments were separated by agarose gel electrophoresis, stained with ethidium bromide, visualised under UV-light and photographed. 


\section{Results}

A total of 215 yeast isolates, 155 of $S$. cerevisiae and 60 of non-Saccharomyces yeasts, were obtained from five varieties of wine grapes in small scale fermentations (Figure 1).

The fermentation times of the cultivars from Verdejo, Sauvignon Blanc and Tempranillo grapes were between 7 and 8 days, whereas the fermentation times for cultivars from Cabernet Sauvignon and Grenache grapes were between 13 and 15 days. The grape cultivars Tempranillo, Verdejo and Sauvignon Blanc had a total of 98 yeast isolates comprised of $56 \mathrm{~S}$. cerevisiae isolates and 42 non-Saccharomyces isolates. The grape varieties Cabernet Sauvignon and Grenache had a total of 117 yeasts comprised of $99 \mathrm{~S}$. cerevisiae isolates and 18 nonSaccharomyces isolates. Among the non-Saccharomyces species isolated from the grape musts, Rhodotorula mucilaginosa was the most common species, followed by Pichia kudriavzevii, Candida parapsilosis, Meyerozyma guilliermondii, Wickerhamomyces anomalus, Kloeckera apis, P. manshurica, C. orthopsilosis and C. zemplinina. The population counts of these yeasts ranged among 1.0 to $19 \times 10^{5} \mathrm{cfu} / \mathrm{mL}$.

A total of 155 isolates of $S$. cerevisiae were compared by mitochondrial DNA restriction analysis. The profiles P1 (represented by strains LMA-V68 and LMA-V132), P2 (represented by strain LMA-V80), P3 (represented by strain LMA-V148), P4 (represented by strain LMA-V152) and P5 (represented by strains $S$. cerevisiae E and strain LMA-V65) were found among the 155 isolates of $S$. cerevisiae obtained in this study (Figure 2). Figure 3 shows the distribution of these five molecular profiles among the grape varieties fermented in laboratory scale. Figure 4 shows the molecular profiles of commercial strains $S$. cerevisiae A (profile P6), S. cerevisiae B (P7), S. cerevisiae C (P8), S. cerevisiae D (P5), S. bayanus F (P8) and $S$. cerevisiae $\mathrm{E}$ (P5). These mtDNA profiles were compared with indigenous strains LMA-V68 (P1), LMA-V80 (P2) and LMA-V65 (profile P5, isolated from fermented grapes), as shown in the same figure. The commercial yeast $S$. cerevisiae $\mathrm{D}$ and $S$. cerevisiae $\mathrm{E}$ showed the same restriction profile (P5) as yeast LMA-V65 (Figure 4), which was isolated from grapes in our study. Commercial strains $S$. cerevisiae $\mathrm{C}$ and $S$. bayanus $\mathrm{F}$ have identical restriction mtDNA profiles (profile P8).

In this study, the molecular profile P1 was prevalent among the strains of $S$. cerevisiae isolated from São Francisco Valley, comprising $45.8 \%$ of the total 155 strains tested, followed by the profile P5 (41.3\%), P4 (7.1\%), P3 (3.2\%) and P2 (2.6\%) (Figure 2). The molecular profile P1 was found in all five grape cultivars studied. The molecular profile P5 was found in the grape varieties Grenache, Cabernet Sauvignon (in the highest percentage) and Sauvignon Blanc. This molecular profile was identical to the commercial strains $S$. cerevisiae D and E. The strains that have the molecular profile $\mathrm{P} 3$ were found in grape cultivars Tempranillo and Sauvignon Blanc, and the molecular profile P2 was found only in Cabernet Sauvignon.

\section{Discussion}

The differences in the number of yeasts isolated from each grape cultivar may be related to the fermentation time of each sample; spontaneous fermentation time was lower (on average 7-8 days) for the must of the varieties Tempranillo, Verdejo and Sauvignon Blanc than for the varieties Cabernet Sauvignon and Grenache (an average of 1315 days). The grape's yeast microbiota depends on a variety of factors, including grape variety and the vineyard's age

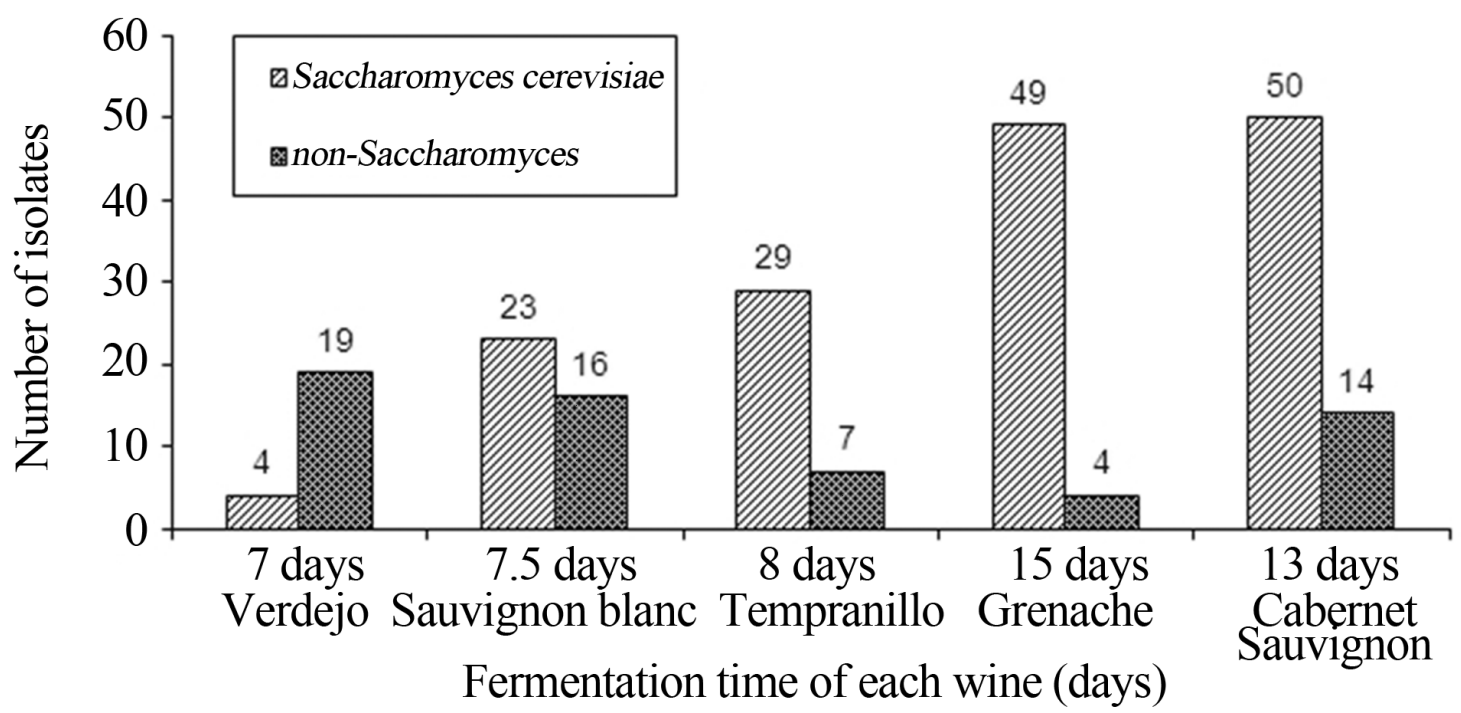

Figure 1 - Number of isolates of Saccharomyces cerevisiae and non-Saccharomyces yeasts obtained from fermented must and fermentation time of different grapes (Vitis vinifera L.) of the São Francisco Valley. 


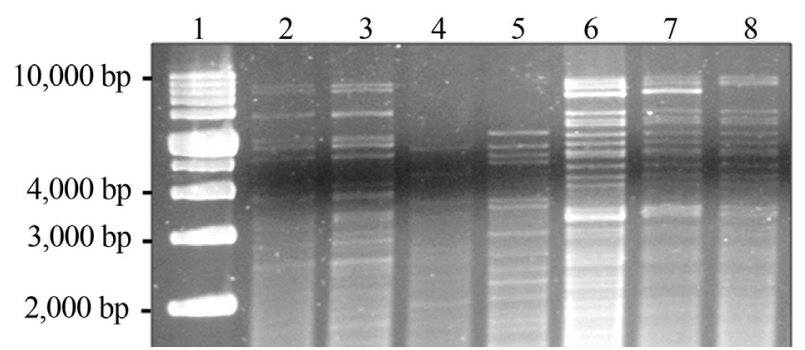

Figure 2 - Patterns generated by mitochondrial DNA-RFLP with Hinfl restriction endonuclease of indigenous Saccharomyces cerevisiae isolates from fermented grape must (Vitis vinifera $\mathrm{L}$.). Lanes: 1, $1 \mathrm{~Kb}$ plus DNA Ladder; 2, profile P5 (strain LMA-V65); 3, profile P5 (commercial $S$. cerevisiae E); 4, profile P2 (strain LMA-V80); 5, profile P3 (strain LMA-V148); 6, profile P1 (strain LMA-V68); 7, profile P1 (strain LMA-V132); 8, profile P4 (strain LMA-V152).

(Schuller et al., 2005; Lederer et al., 2013). Saccharomyces cerevisiae isolates produced five different mtDNA-RFLP molecular profiles (Figure 2). The mtDNA-RFLP analysis indicated a low genetic polymorphism of the $S$. cerevisiae populations associated with the grapes studied, and this result may be linked to the age of grape cultivars studied in the São Francisco Valley. These cultivars were approximately three years old during our study, and this time may not have been sufficient for the colonisation of the grapes by a greater number of indigenous strains of $S$. cerevisiae. Schuller et al. (2005) found different results in an ecological survey of $S$. cerevisiae strains from vineyards in the Vinho Verde Region of Portugal. A total of 1,620 yeast isolates were obtained from 54 spontaneous grape fermentations collected in 3 vineyards. A total of 297 different profiles were found by mtDNA-RFLP. It is possible these vineyards were already well established in the region, which would explain the large number of strains found with different patterns of mtDNA. The differences found could also be explained by the skin morphology of the grapes. For example, Sauvignon blanc presented high quantity of bloom in the thin skins, while in the grapes of Verdejo, the skins were very thick and presented less quantity of bloom, as compared with the skins from Sauvignon blanc. In our

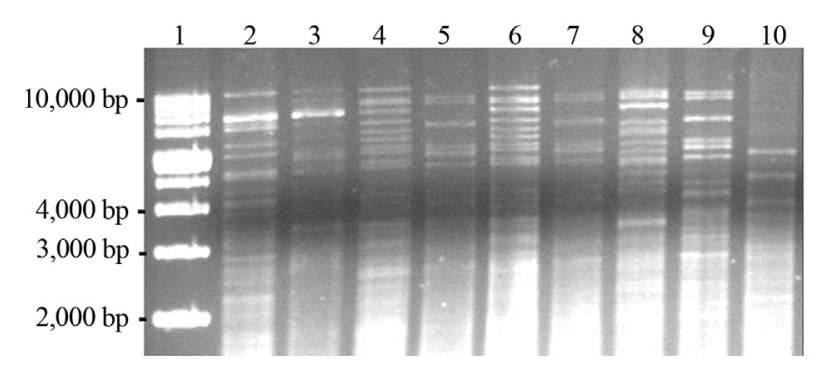

Figure 4 - Patterns generated by mitochondrial DNA-RFLP with Hinfl restriction endonuclease of indigenous Saccharomyces cerevisiae and commercial strains. Lanes: 1, $1 \mathrm{~Kb}$ plus DNA Ladder; 2, commercial yeast $S$. cerevisiae A, profile P6; 3, commercial $S$. cerevisiae B, profile P7; 4, commercial $S$. cerevisiae C, profile P8; 5 , commercial $S$. cerevisiae D, profile $\mathrm{P} 5$; 6, commercial $S$. bayanus F, profile P8; 7, commercial $S$. cerevisiae E, profile P5; 8, strain LMA-V68, profile P1; 9, strain LMA-V65, profile P5; 10, strain LMA-V80, profile P2.

study, Sauvignon Blanc grape fermentation presented four different mtDNA patterns of $S$. cerevisiae while Verdejo only one.

Analyses of the restriction mtDNA profiles suggest that the commercial strains $S$. cerevisiae D and E (P5 molecular profile) are widespread in São Francisco Valley vineyards. One explanation for this is the use of wine production residuals as fertiliser in the region.

The results of molecular profiles shown in Figure 4 suggest that a single strain could be marketed by different companies with different names. The commercial yeast $S$. cerevisiae D and S. cerevisiae E showed the same restriction mtDNA profile. Commercial strain $S$. bayanus $\mathrm{F}$ and commercial strain $S$. cerevisiae $\mathrm{C}$ had also an identical mtDNA profile. Fernández-Espinar et al. (2001) showed that some commercial strains had identical molecular profiles, and several companies are commercialising the same strain under different names. Our results suggest that the same problem seems to be occurring with the commercial strains of S. cerevisiae in the São Francisco Valley.

Species belonging to the genera Pichia, Candida, Meyerozyma, Rhodotorula and Kloeckera isolated in our study were also frequently isolated in other studies of grape

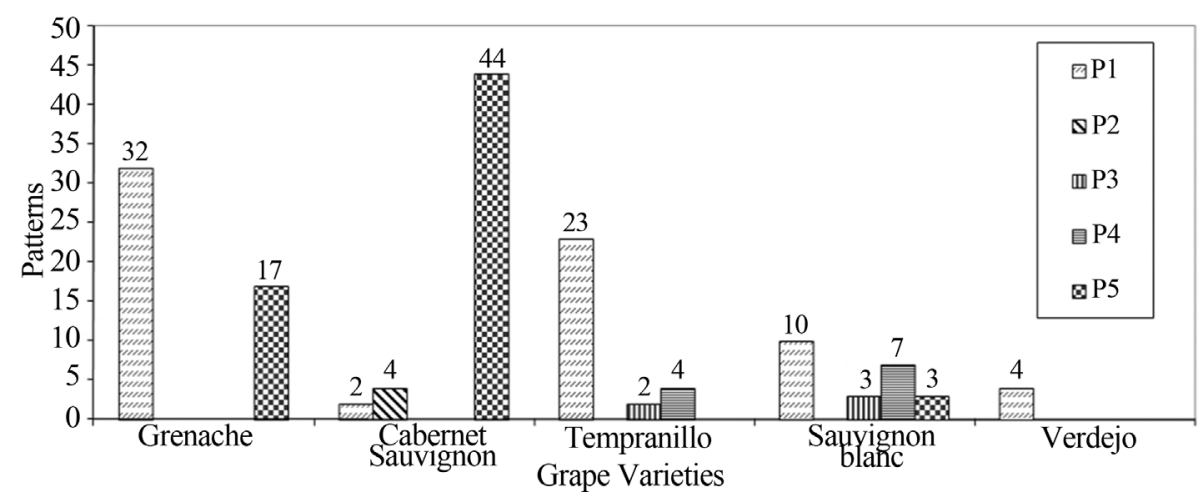

Figure 3 - Number of isolates of Saccharomyces cerevisiae yeasts for each pattern of mitochondrial DNA-RFLP with HinfI restriction endonuclease obtained from different grape varieties studied in the São Francisco Valley region, northeastern Brazil. 
fermentation for wine production (Esteve-Zarzoso et al., 2000; Clemente-Jimenez et al., 2004; González et al., 2007; Urso et al., 2008; Settanni et al., 2012; Ortiz et al., 2013; Wang and Liu, 2013), and they are a minor component of grape fermentation microbiota. Rh. mucilaginosa has been associated with the phylloplane (Fonseca and Inácio, 2006) and can be a coloniser of the surface of grapes. Wickerhamomyces anomalus and M. guilliermondi have been isolated from grape must and winemaking equipment (Barrajón et al., 2009; Kurtzman et al., 2011; Settanni et al., 2012). Another species isolated in this work is Candida zemplinina, which has been isolated from botrytis-affected ("botrytised") wine fermentations in the Tokaj (Hungary) wine region (Sipiczki, 2003), botrytised grapes in California (Mills et al., 2002; Lederer et al., 2013), spontaneous fermentations of Austrian wines (Lopandic et al., 2008) and from grapes, must and wines of different regions of Italy (Tofalo et al., 2012). These findings suggest that this strain is related to fermented grape musts.

Indigenous strains of $S$. cerevisiae may contribute to the overall sensorial quality of wine because they are more competitive in their local environmental conditions than non-indigenous strains. Indigenous strains isolated from grapes of the São Francisco Valley can be further tested as potential starters for wine production. Fermenting yeast populations have never been characterized before in this region, and the knowledge about the occurrence of indigenous $S$. cerevisiae strains in São Francisco Valley represents an initial step for further studies for the development a regional wine start strain.

\section{Acknowledgments}

This work was funded by Conselho Nacional de Desenvolvimento Cientifico e Tecnológico (CNPq - Brazil), Financiadora de Estudos e Projetos (FINEP - project INOVASE) and Fundação do Amparo a Pesquisa do Estado de Minas Gerais (FAPEMIG). We thank the farm Ouro Verde/Miolo (BA) by the technical support during the grape collection.

\section{References}

Barrajón N, Arévalo-Villena M, Rodríguez-Aragón LJ, Briones A (2009) Ecological study of wine yeast in inoculated vats from La Mancha region. Food Control 20:778-783.

Capece A, Romaniello R, Siesto G, Romano P (2012) Diversity of Saccharomyces cerevisiae yeasts associated to spontaneously fermenting grapes from an Italian "heroic vinegrowing area. Food Microbiol 31:159-166.

Ciani M, Mannazzu I, Marinangeli P, Clementi F, Martini A (2004) Contribution of winery-resident Saccharomyces cerevisiae strains to spontaneous grape must fermentation. Antonie van Leeuwenhoek 85:159-164.

Clemente-Jimenez JM, Mingorance-Cazorla L, Martínez-Rodríguez S, Las Heras-Vázquez FJ, Rodríguez-Vico F (2004) Molecular characterization and oenological properties of wine yeasts isolated during spontaneous fermentation of six varieties of grape must. Food Microbiol 21:149-155.

Esteve-Zarzoso B, Gostíncar A, Bobet R, Uruburu F, Querol A (2000) Selection and molecular characterization of wine yeasts isolated from the 'El Penedès' area (Spain). Food Microbiol 17: 553-562.

Fernández-Espinar MT, López V, Ramón D, Bartra E, Querol A (2001) Study of the authenticity of commercial wine yeast strains by molecular techniques. Int J Food Microbiol 70:110.

Fleet GH (2008) Wine yeasts for the future. FEMS Yeast Res 8:979-995.

Fonseca A, Inácio J (2006) Phylloplane Yeasts. In: Rosa, C.A., Péter, G. (eds) Biodiversity and Ecophysiology of Yeasts. Springer-Verlag, Berlin, Germany, pp. 263-301.

González SS, Barrio E, Querol A (2007) Molecular identification and characterization of wine yeasts isolated from Tenerife (Canary Island, Spain). J Appl Microbiol 102:1018-1025.

Kurtzman CP, Fell JW, Boekhout T (2011) The Yeasts - A Taxonomic Study. 5th. ed. Elsevier Science Plub. B.V., Amsterdm, The Netherlands.

Lachance MA, Bowles JM, Starmer WT, Barker JSF (1999) Kodamaea kakaduensis and Candida tolerans, two new yeast species from Australian Hibiscus flowers. Can J Microbiol 45:172-177.

Lederer MA, Nielsen DS, Toldam-Andersen TB, Herrmann JV, Arneborg N (2013) Yeast species associated with different wine grapes varieties in Denmark. Acta Agr Scand Section B soil Plant Sci 63:89-96.

Lopandic K, Tiefenbrunner W, Gangl H, Mandl K, Berger S, Leitner G, Abd-Ellah GA, Querol A, Gardner RC, Sterflinger K, Prillinger H (2008) Molecular profiling of yeasts isolated during spontaneous fermentations of Austrian wines. FEMS Yeast Res 8:1063-1075.

Mills DA, Johannsen EA, Cocolin L (2002) Yeast diversity and persistence in botrytis-affected wine fermentations. Appl Environ Microbiol 68:4884-4893.

Ortiz MJ, Barrajón N, Baffi MA, Villena MA, Briones A (2013) Spontaneous must fermentation: Identification and biotechnological properties. LWT - Food Sci Technol 50:372-377.

Querol A, Barrio E, Huerta T, Ramón D (1992) Molecular monitoring of wine fermentations conducted by active dry yeasts strains. Appl Environ Microbiol 58:2948-2953.

Santos JI (2008) Vinhos: O Essencial. SENAC, São Paulo.

Schuller D, Alves H, Dequin S, Casal M (2005) Ecological survey of Saccharomyces cerevisiae strains from vineyards in the Vinho Verde region of Portugal. FEMS Microbiol Ecol 51:167-177.

Settanni L, Sannino C, Francesca N, Guarcello R, Moschetti G (2012) Yeast ecology of vineyards within Marsala wine area (western Sicily) in two consecutive vintages and selection of autochthonous Saccharomyces cerevisiae strains. J Biosci Bioeng 114:606-614.

Sipiczki M (2003) Candida zemplinina sp. nov., an osmotolerant and psychrotolerant yeast that ferments sweet botrytized wines. Int J Syst Evol Microbiol 53:2079-2083.

Tofalo R, Schirone M, Torriani S, Rantsiou K, Cocolin L, Perpetuini G, Suzzi G (2012) Diversity of Candida zemplinina strains from grapes and Italian wines. Food Microbiol 29:18-26. 
Urso R, Rantsiou K, Dolci P, Rolle L, Comi G, Cocolin L (2008) Yeast biodiversity and dynamics during sweet wine production as determined by molecular rmethods. FEMS Yeast Res 8:1053-1062.

Valero E, Cambon B, Schüller D, Casal M, Dequin S (2007) Biodiversity of Saccharomyces yeast strains from grape ber- ries of wine-producing areas using starter commercial yeasts. FEMS Yeast Res 7:317-329.

Wang C, Liu Y (2013) Dynamic study of yeast species and Saccharomyces cerevisiae strains during the spontaneous fermentations of Muscat blanc in Jingayang, China. Food Microbiol 33:172-177.

All the content of the journal, except where otherwise noted, is licensed under a Creative Commons License CC BY-NC. 
Supplementary Information

301 Microbial chemical study

302 Obtaining of the extract and fractionation procedure

303 The product Schizochytrium sp was marketed as AlgaMac 2000 by Aquafauna Bio-

304 Marine of Hawthorne, CA, USA, and a sample of $110 \mathrm{~g}$ of spray-dried cells was soaked

305 in dichloromethane (x3, $24 \mathrm{~h})$ and methanol (x3, $24 \mathrm{~h})$. The extracts were filtered by

306 Whatman paper (grade 1) and evaporated, under reduced pressure, in a rotary

307 evaporator. Thus, they were combined, dried under high vacuum and stored in the fridge

308 under a nitrogen atmosphere. After that, the resulting crude extract was subjected to

309 partition by polarity in accordance to the diagram presented in the Figure S1.

310 The ${ }^{1} \mathrm{H}-\mathrm{NMR}$ spectrum has showed 7 signals of carboxylic acid protons at $\delta 12.5-11.2$, 311 olefinic protons at $\delta$ 5.9-5.0, geminal to heteroatom protons at $\delta 4.3-3.5$ and aliphatic

312 protons at $\delta 3.0-0.6$.

313 The crude extract was dissolved in $200 \mathrm{ml}$ of water and $200 \mathrm{ml}$ of dichloromethane. The 314 phases were then split in separatory funnel and the aqueous phase was re-extracted with 315 dichloromethane (x3,200 ml each). The organic layers were combined and the solvent 316 evaporated to give $9.64 \mathrm{~g}$ of "liposoluble-0 (Sa-L-0)" fraction.

317 The aqueous phase was extracted with $\mathrm{sec}$-butanol $(\mathrm{x} 3,200 \mathrm{ml}$ each) to give $0.29 \mathrm{~g}$ of

318 the "soluble-1 (Sa-H-1) fraction". Then, an amount of $20 \mathrm{ml}$ of water, $180 \mathrm{ml}$ of

319 methanol and $200 \mathrm{ml}$ of $n$-hexane were added to the "soluble-0 (Sa-L-0)" fraction. The

320 phases were decanted and the methanolic aqueous layer was re-extracted with $n$-hexane

321 until it became clear. The $n$-hexane phases were combined and the solvent was

322 removed, resulting in $1.298 \mathrm{~g}$ of a yellow semi-solid fraction that was called "soluble-1

323 (Sa-L-1)".

324 An amount of $160 \mathrm{ml}$ of water was added to the resulting methanolic aqueous phase, 325 resulting in a $\mathrm{H}_{2} \mathrm{O}: \mathrm{CH}_{3} \mathrm{OH}(50: 50)$ phase which was extracted with $\mathrm{CH}_{2} \mathrm{Cl}_{2}$ (x3, 200 $326 \mathrm{ml}$ each). The organic phases were evaporated to give $0.331 \mathrm{~g}$ of the "soluble-2 (Sa-L-

327 2)" fraction. It was added more methanol to the resulting methanolic aqueous phase and 328 evaporated until dryness, which gave $0.023 \mathrm{~g}$ of the fraction called "soluble-3 (Sa-L-3)".

330 Study of the "crude extract"

331 The following substances were identified by GC-MS:

332 Dodecanoic acid, methyl ester $(4 ; \mathrm{n}=10 ; \mathrm{Rt}=14.343)$

333 Tetradecanoic acid $(3 ; \mathrm{n}=12 ; \mathrm{Rt}=14.746)$

334 1-Hexadecene $(5 ; \mathrm{n}=13 ; \mathrm{Rt}=14.851)$

335 Dodecanoic acid, ethyl ester $(6 ; n=10 ; R t=14.885)$

336 Tridecanoic acid, methyl ester $(4 ; \mathrm{n}=11 ; \mathrm{Rt}=15.128)$

337 Tridecanoic acid, ethyl ester $(6 ; \mathrm{n}=11 ; \mathrm{Rt}=15.632)$

338 Methyl tetradecanoate $(4 ; \mathrm{n}=12 ; \mathrm{Rt}=15.885)$

339 Hexadecanoic acid $(3 ; \mathrm{n}=14 ; \mathrm{Rt}=16.227)$

340 7-Tetradecenoic acid, $(\mathrm{Z})-(7 ; \mathrm{n}=5, \mathrm{~m}=5 ; \mathrm{Rt}=16.331)$

341 Tetradecanoic acid, ethyl ester $(6 ; n=12 ; \mathrm{Rt}=16.354)$ 
342 Pentadecanoic acid, methyl ester $(4 ; \mathrm{n}=13 ; \mathrm{Rt}=16.593)$

343 Pentadecanoic acid, ethyl ester $(6 ; n=13 ; \mathrm{Rt}=17.045)$

344 9-Hexadecenoic acid, methyl ester $(Z)-(8 ; n=5, m=7 ; R t=17.140)$

345 Hexadecanoic acid, methyl ester (4; $\mathrm{n}=14 ; \mathrm{Rt}=17.259)$

346 Pentadecanoic acid, 14-methyl-, methyl ester $(11 ; \mathrm{n}=12 ; \mathrm{Rt}=17.267)$

347 Ethyl 9-hexadecenoate $(9 ; \mathrm{n}=5, \mathrm{~m}=7 ; \mathrm{Rt}=17.570)$

348 Hexadecanoic acid, ethyl ester $(6 ; n=14 ; \mathrm{Rt}=17.683)$

349 9-Octadecenoic acid (Z)-, 2-hydroxy-1-(hydroxymethyl)ethyl ester (15; Rt= 18.413)

350 9-Octadecenoic acid, methyl ester $(8 ; \mathrm{n}=7, \mathrm{~m}=7 ; \mathrm{Rt}=18.416)$

351 Octadecanoic acid, methyl ester $(4 ; \mathrm{n}=16 ; \mathrm{Rt}=18.533)$

352 9-Hexadecenoic acid, eicosyl ester, $(Z)-(16 ; n=19 ; \mathrm{Rt}=18.764)$

353 Octadecanoic acid, ethyl ester $(6 ; n=16 ; \mathrm{Rt}=18.954)$

354

355 Study of the "liposoluble-0 (Sa-L-0)" fraction

356 The following substances were identified by GC-MS:

357 Tridecane $(1 ; \mathrm{n}=10 ; \mathrm{Rt}=12.384)$

358 Dodecanoic acid, methyl ester $(4 ; \mathrm{n}=10 ; \mathrm{Rt}=14.422)$

359 Tetradecanoic acid $(3 ; \mathrm{n}=12 ; \mathrm{Rt}=14.862)$

360 Methyl tetradecanoate $(4 ; \mathrm{n}=12 ; \mathrm{Rt}=15.957)$

361 Hexadecanoic acid $(3 ; \mathrm{n}=14 ; \mathrm{Rt}=16.354)$

362 9-Hexadecenoic acid, methyl ester, $(Z)-(8 ; n=5, m=7 ; R t=17.230)$

363 Hexadecanoic acid, methyl ester $(4 ; \mathrm{n}=14 ; \mathrm{Rt}=17.344)$

364 Hexadecanoic acid, 1-(hydroxymethyl)-1,2-ethanediyl ester $(14 ; \mathrm{Rt}=17.714)$

365 11-Octadecenoic acid, methyl ester $(8 ; n=5, m=9 ; \mathrm{Rt}=18.514)$

366 Cholesterol $(22 ; \mathrm{Rt}=18.870)$

367 1-Dodecanol, 3,7,11-trimethyl- (21; Rt=19.038)

369 Study of the "liposoluble-1 (Sa-L-1)" fraction

370 In the ${ }^{1} \mathrm{H}-\mathrm{NMR}$ spectrum of this mixture were detected olefinic protons ( $\delta 5.1$ to 5.3 ),

371 geminal to heteroatom protons $(\delta 4.0$ to 4.2$)$ and typical protons of aliphatic

372 hydrocarbon chains $(\delta 2.9-0.7)$. In the ${ }^{13} \mathrm{C}$-NMR spectrum were observed six carbonyl

373 carbons $(\delta 178-187), 16$ olefinic carbons $(\delta 130.939$ and 128.859$)$, four geminal to

374 heteroatom carbons $(\delta 77.543-65.914)$ and 34 signals of aliphatic chains $(\delta 37.469-$

375 14.132). The following volatile substances were identified by GC-MS:

376 Tridecane $(1 ; \mathrm{n}=10 ; \mathrm{Rt}=12.380)$

377 Cyclohexanol, 2-methyl-5-(1-methylethyl)-, $(1 \alpha, 2 \beta, 5 \beta)-(19 ; \mathrm{Rt}=12.789)$

378 1-Pentadecene $(5 ; \mathrm{n}=12 ; \mathrm{Rt}=13.236)$ 
Tetradecane $(1 ; \mathrm{n}=11 ; \mathrm{Rt}=13.299)$

380 Pentadecane $(1 ; \mathrm{n}=12 ; \mathrm{Rt}=14.156)$

381 Undecanoic acid, 10-methyl-, methyl ester (11; $\mathrm{n}=8$; Rt=14.412)

382 Tetradecanoic acid $(3 ; \mathrm{n}=12 ; \mathrm{Rt}=14.858)$

383 9-Hexadecenoic acid, tetradecyl ester, $(Z)-(16 ; n=13 ; R t=15.609)$

384 Stigmasterol (23; Rt $=15.672)$

385 Methyl tetradecanoate $(4 ; \mathrm{n}=12 ; \mathrm{R} t=15.952)$

386 Hexadecanoic acid $(3 ; \mathrm{n}=14 ; \mathrm{Rt}=16.348)$

387 7-Tetradecenoic acid, $(\mathrm{Z})-(7 ; \mathrm{n}=5, \mathrm{~m}=5 ; \mathrm{Rt}=16.474)$

388 Pentadecanoic acid, methyl ester $(4 ; \mathrm{n}=13 ; \mathrm{Rt}=16.664)$

389 9-Hexadecenoic acid, methyl ester, $(Z)-(8 ; n=5, m=7 ; R t=17.223)$

390 Pentadecanoic acid, 14-methyl-, methyl ester $(11 ; \mathrm{n}=12 ; \mathrm{Rt}=17.339)$

391 9-Octadecenoic acid (Z)-, 2-hydroxy-1-(hydroxymethyl)ethyl ester (15; Rt=18.504)

392 Two different fractions (Sa-L-1-a and Sa-L-1-b) were obtained by gel filtration

393 (Sephadex LH-20; eluting with $\mathrm{CH}_{3} \mathrm{OH}: \mathrm{CH}_{2} \mathrm{Cl}_{2} ; 50: 50$ ) after checking by analytical

394 TLC.

395

396 Study of the "liposoluble-1-a (Sa-L-1-a)" fraction

397 The following substances were identified by GC-MS:

398 Tetradecanoic, acid $(3 ; \mathrm{n}=12 ; \mathrm{Rt}=14.748)$

399 Methyl tetradecanoate $(4 ; \mathrm{n}=12 ; \mathrm{Rt}=15.879)$

400 Tetradecanoic acid, ethyl ester $(6 ; \mathrm{n}=12 ; \mathrm{Rt}=16.356)$

401 9-Hexadecenoic acid, methyl ester, $(Z)-(8 ; n=5, m=7 ; R t=17.155)$

402 Hexadecanoic acid, methyl ester $(4 ; n=14 ; \mathrm{Rt}=17.270)$

403 Hexadecanoic acid, 1-(hydroxymethyl)-1,2-ethanediyl ester $(14 ; \mathrm{Rt}=17.578)$

404 Hexadecanoic acid, ethyl ester $(6 ; \mathrm{n}=14 ; \mathrm{Rt}=17.693)$

405 11-Octadecenoic acid, methyl ester $(8 ; n=5, m=9 ; R t=18.423)$

406 From this fraction (Sa-L-1-a), three different sub-fractions were obtained by semi-

407 preparative HPLC (normal phase, hexane: EtOAc; 80: 20): Liposoluble-1-a-1 (Sa-L-1-

408 a-1, $350 \mathrm{mg}$ ), Liposoluble-1-a-2 (Sa-L-1-a-2, $56 \mathrm{mg}$ ) and Liposoluble-1-a-3 (Sa-L-1-a-

$4093,5 \mathrm{mg})$.

410

411 Study of the (Sa-L-1-a-1) fraction

412 In the ${ }^{1} \mathrm{H}-\mathrm{NMR}$ spectrum of this fraction were observed olefinic protons $(\delta 5.1-5.5)$,

413 geminal to heteroatom protons $(\delta 4.0-4.2$, ddd $)$ and typical protons of aliphatic

414 hydrocarbon chains $(\delta 2.9-0.7)$. In the ${ }^{13} \mathrm{C}-\mathrm{NMR}$ spectrum were observed six carbonyl

415 carbons $(\delta 175.0-185.0), 14$ olefinic carbons $(\delta 137.0$ and 125.0$)$, several geminal to

416 heteroatom carbons $(\delta 60.0-70,0)$ and 28 signals of aliphatic chains $(\delta 37.469-14.132)$. 
417 Its purification was approached by preparative TLC (normal phase, $n$-hexane: EtOAc,

418 90: 10) but no volatile compounds were identified by GC-MS.

419

420 Study of the (Sa-L-1-a-2) fraction

421 In the ${ }^{1} \mathrm{H}-\mathrm{NMR}$ spectrum of this mixture were detected olefinic protons $(\delta 5.1-5.3)$,

422 geminal to heteroatom protons $(\delta 3.3-4.2)$ and typical protons of aliphatic hydrocarbon

423 chains $(\delta 2.9-0.7)$. No compounds were identified by GC-MS in this fraction.

424

425 Study of the (Sa-L-1-a-3) fraction

426 It is a homogeneous fraction reported by analytical HPLC and TLC (normal phase,

427 hexane: EtOAc; 80: 20, $\mathrm{Rf}=0.17$ ). In the ${ }^{1} \mathrm{H}-\mathrm{NMR}$ spectrum were detected olefinic

428 protons ( $\delta 4.9-5.6)$, geminal to heteroatom protons $(\delta 3.4-4.8)$ and methylenes/

429 methines $(\delta 1.7-0.7)$ suggesting a lipid mixture. The following volatile substances were

430 identified by GC-MS:

431 1-Eicosanol (2; Rt= 16.330)

432 Hexadecanoic acid, ethyl ester $(6 ; n=14 ; \mathrm{Rt}=17.685)$

433 Erucic Acid $(7 ; n=7, m=11 ; \mathrm{Rt}=19.775)$

434

435 Study of the "liposoluble-2 (Sa-L-2)" fraction

436 By TLC (normal phase, $n$-Hexane: EtOAc; 80: 20, $\mathrm{Rf}=0.81$ ), the ${ }^{1} \mathrm{H}-\mathrm{NMR}$ and the ${ }^{13} \mathrm{C}$ -

437 NMR spectra are presented as a lipid mixture of substances. The following substances

438 were identified by GC-MS:

439 Cyclohexanol, 4-methyl-1-(1-methylethyl)- (18; Rt=12.841)

440 Stearic acid, 1,2,3-propanetriyl ester $(12 ; \mathrm{n}=16 ; \mathrm{Rt}=14.590)$

441 Tetradecanoic acid $(3 ; \mathrm{n}=12 ; \mathrm{Rt}=14.845)$

442 Methyl tetradecanoate $(4 ; \mathrm{n}=12 ; \mathrm{Rt}=15.939)$

443 Hexadecanoic acid $(3 ; \mathrm{n}=14 ; \mathrm{Rt}=16.334)$

444 Tetradecanoic acid, ethyl ester $(6 ; \mathrm{n}=12 ; \mathrm{Rt}=16.424)$

445 Pentadecanoic acid, ethyl ester $(6 ; \mathrm{n}=13 ; \mathrm{Rt}=17.096)$

446 9-Hexadecenoic acid, methyl ester, $(Z)-(8 ; n=5, m=7 ; R t=17.210)$

447 Hexadecanoic acid, methyl ester $(4 ; \mathrm{n}=14 ; \mathrm{Rt}=17.326)$

448 Germanicol (24; Rt $=17.427)$

449 Ethyl 9-hexadecenoate $(9 ; \mathrm{n}=5, \mathrm{~m}=7 ; \mathrm{Rt}=17.644)$

450 Hexadecanoic acid, ethyl ester $(6 ; \mathrm{n}=14 ; \mathrm{Rt}=17.746)$

451 Hexadecanoic acid, 1-(hydroxymethyl)-1,2-ethanediyl ester $(14 ; \mathrm{Rt}=17.914)$

452

453 Study of the "liposoluble-3 (Sa-L-3)" fraction

454 The following substances were identified by GC-MS: 
Tridecane $(1 ; \mathrm{n}=10 ; \mathrm{Rt}=12.368)$

456 4-Hydroxy-3,4,6-trimethylhept-5-enoic acid lactone $(20 ; \mathrm{Rt}=12.803)$

457 Cyclohexanol, 4-methyl-1-(1-methylethyl)- $(18 ; \mathrm{Rt}=12.841)$

458 1-Pentadecene $(5 ; \mathrm{n}=12 ; \mathrm{Rt}=13.224)$

459 Pentadecane $(1 ; \mathrm{n}=12 ; \mathrm{Rt}=14.146)$

460 1-Hexadecene $(5 ; \mathrm{n}=13 ; \mathrm{Rt}=14.899)$

461 1-Octadecene $(5 ; \mathrm{n}=15 ; \mathrm{R} \mathrm{t}=16.388)$

462 Pentadecanoic acid, 14-methyl-, methyl ester $(11 ; \mathrm{n}=12 ; \mathrm{Rt}=17.327)$

463

464 Study of the "hydrosoluble-1 (Sa-H-1)" fraction

465 The following substances were identified by GC-MS:

466 2H-Pyran-2-one, tetrahydro-4-hydroxy-4-methyl- $(17 ; \mathrm{Rt}=12.484)$

467 Cyclohexanol, 4-methyl-1-(1-methylethyl)- (18; Rt=12.828)

468 Tetradecane $(1 ; \mathrm{n}=11 ; \mathrm{Rt}=13.275)$

469 Pentadecane $(1 ; \mathrm{n}=12 ; \mathrm{Rt}=14.133)$

470 Trinonanoin $(12 ; \mathrm{n}=7 ; \mathrm{Rt}=14.260)$

471 Methyl tetradecanoate $(4 ; \mathrm{n}=12 ; \mathrm{Rt}=15.930)$

472 9-Hexadecenoic acid, methyl ester, $(Z)-(8 ; n=5, m=7 ; R t=17.200)$

473 Hexadecanoic acid, methyl ester $(4 ; \mathrm{n}=13 ; \mathrm{Rt}=17.316)$

474 Octadecanoic acid, 2-hydroxy-1,3-propanediyl ester $(14 ; \mathrm{Rt}=17.735)$

475 9,12-Octadecadienoic acid (Z,Z)-, methyl ester $(10 ; \mathrm{Rt}=18.413)$

476 Docosanoic acid, 1,2,3-propanetriyl ester $(12 ; n=20 ; R t=19.206)$

477

$==\mathrm{h} 3$ Preparation of ethylic saturated biodiesel

479 A sample of $100 \mathrm{~g}$ of spray-dried cells of Schizochytrium sp was soaked in

480 dichloromethane (x3, $24 \mathrm{~h})$ and methanol (x3, $24 \mathrm{~h})$. The extracts were combined and

481 concentrated to give the "crude extract" (15.77 g) which was adsorbed on silica gel and

482 chromatographed on a normal phase column $\left(\mathrm{SiO}_{2}\right.$ as adsorbent and $n$-hexane/ EtOAc

483 as eluent, with increasing amounts of EtOAc).

484 Monitoring by TLC allowed grouping the fractions in six sub-fractions (Sa-1 to Sa-6).

485 The fourth (Sa-4) was taken as the majority $(10.83 \mathrm{~g}, 68.69 \% \mathrm{w} / \mathrm{w}$ crude extract) and

486 the ${ }^{1} \mathrm{H}-\mathrm{NMR}$ spectroscopy was made up mostly of triglycerides of saturated fatty acids

$487\{\delta 4.20$ (br m), 3.72 (br m), 2.35 (br m), 1.65 (br m), 1.29 (br s), 0.92 (br m) \}.

488 A sample of these lipids (1.398 g) was dissolved in $50 \mathrm{ml}$ of absolute ethanol (analytical

489 grade), which was added two drops of perchloric acid (60\%), left under reflux (3 h) and

490 allowed to cool to room temperature with stirring overnight (12 h). It was, then, added

$4910.155 \mathrm{~g}$ of sodium bicarbonate and stirred for $2.5 \mathrm{~h}$. An amount of anhydrous disodium

492 sulphate $(0.5 \mathrm{~g})$ was added and stirred for $30 \mathrm{~min}$. So, it was added $0.3 \mathrm{~g}$ of charcoal to

493 the mixture, stirred for another $30 \mathrm{~min}$, filtered through Whatman $\mathrm{N}^{\mathrm{o}} 1$, and the ethanol 
494 eliminated at reduced pressure in rotary evaporator. The resulting final product was an 495 oil (1.603 g) which spectrum of ${ }^{1} \mathrm{H}-\mathrm{NMR}$ reveals the presence of ethyl esters of fatty 496 acids impurified by glycerol $(\delta 3.8-3.9)$.

497 Then, a chromatographic column was prepared with this product $\left(\mathrm{SiO}_{2}\right.$ as adsorbent and $498 n$-hexane/ EtOAc as eluent, with increasing amounts of EtOAc), which led to a sample 499 of fully saturated ethyl biodiesel $(0.582 \mathrm{~g}, 41.60 \% \mathrm{w} / \mathrm{w}$ compared to crude extract $) .{ }^{1} \mathrm{H}-$ $500 \quad \mathrm{NMR}\left(\mathrm{CDCl}_{3}\right) \delta 4.13(2 \mathrm{H}, \mathrm{q}, \mathrm{J}=7.13 \mathrm{~Hz}), 2.29(2 \mathrm{H}, \mathrm{t}, \mathrm{J}=7.47 \mathrm{~Hz}), 1.44(2 \mathrm{H}, \mathrm{m}), 1.25$ $501(31 \mathrm{H}, \mathrm{s}), 0.88(3 \mathrm{H}, \mathrm{t}, \mathrm{J}=7.13 \mathrm{~Hz})$. The Integral curve of ${ }^{1} \mathrm{H}-\mathrm{NMR}$ spectrum deduces a 502 chain length average of 15.52 carbon atoms, which was confirmed by ${ }^{13} \mathrm{C}-\mathrm{NMR}$ 503 spectrum $(\delta 60.59,34.78,32.34,30.08,29.85,25.39,23.15,14.54)$, where the signal 504 corresponding to the hydrocarboned long chain ( $\delta 30.08$ and 29.85) appears particularly 505 intense. 